\title{
Percutaneous interventions in pulmonary artery embolism
}

\author{
Lovel Giunio*, Branimir Marković, Anteo Bradarić, Jakša Zanchi \\ University Hospital Center Split, Split, Croatia
}

\begin{abstract}
Massive pulmonary embolism is a life-threatening condition with a high early mortality due to hemodynamic instability, acute right ventricular failure, and cardiogenic shock. Submassive PE, as defined by right ventricular failure or troponin elevation, can result in life-threatening sequelae if treatment is not initiated promptly. Treatment of PE is based on prompt risk stratification and aggressive therapeutic strategies. Risk stratification is oriented toward evaluation of the risk of early death, classifying patients as high risk versus intermediate or low risk, replacing the terminology of acute massive, submassive or nonmassive pulmonary embolism.

As soon as the diagnosis is suspected, an IV bolus of unfractionated heparin should be administered. In addition to anticoagulation, thrombolysis is the mainstay of therapy in high-risk pulmonary embolism. With the advent of endovascular technologies, various catheter-based thrombectomy and thrombolytic devices are available to treat patients with massive or submassive PE. Catheter thrombectomy appears to be particularly useful if surgical embolectomy is not available or the patient has contraindications to thrombolysis because of an increased bleeding risk, such as prior sur-
\end{abstract}

gery, trauma, or cancer. Although no controlled clinical trials are available, data from registries and cohort studies indicate that the clinical outcomes after surgical and catheter embolectomy may be comparable.

In this article, the authors' institutional experience with catheter-directed thrombolytic therapy in patients with acute massive PE during a recent 10 -year period is presented.

KEYWORDS: pulmonary embolism, catheter-based therapies, thrombus fragmentation, thrombolysis.

Received: $11^{\text {th }}$ Mar 2013

*Address for correspondence: Klinički bolnički centar Split, Šoltanska 1, HR-21000 Split, Croatia.

Phone: +385-21-55-71-11

Email: lovelgiunio@ hotmail.com 